\title{
Studies on Underwater Electric Discharge and Associated Pressure Waves
}

This paper was downloaded from TechRxiv (https://www.techrxiv.org).

\section{LICENSE}

CC BY 4.0

\section{SUBMISSION DATE / POSTED DATE}

08-09-2021 / 10-09-2021

\section{CITATION}

Chernyak, Valeriy; lukhymenko, Vitalii; Martysh, Evgen; Nedybaliuk, Oleg; Fedorovich, Oleg; Shevel, Valeriy; et al. (2021): Studies on Underwater Electric Discharge and Associated Pressure Waves. TechRxiv. Preprint. https://doi.org/10.36227/techrxiv.16586678.v1

$\mathrm{DOI}$

10.36227/techrxiv.16586678.v1 


\title{
Studies on Underwater Electric Discharge and Associated Pressure Waves
}

\author{
V. Ya. Chernyak, V. V. Iukhymenko, Eug. V. Martysh, Ol. A. Nedybaliuk, O. A. Fedorovich, V. M. \\ Shevel and V. S. Popkov
}

\begin{abstract}
Pulsed electric discharges in a liquid with the sufficiently wide range of energy contributions to them can generate diverging shock waves. A significant part of this energy is carried away by these waves from the center of the system to its periphery. At the same time, pulsed plasma-liquid systems limited by reflecting walls of both cylindrical and spherical geometry are insufficiently studied. A fundamental feature of such systems is the generation of a sequence of both diverging and converging (reflected) shock waves by a single pulse discharge. It was shown earlier that in a cylindrical plasma-liquid system with a height of the cylinder (h) comparable with the interelectrode distance (d), radius of the cylinder base $R$ (at $R$ >> h), when discharge current is increased, the ratio of the second diverging shock wave amplitude to the amplitude of the first diverging shock wave can be $\rightarrow 1$. This leads to effective return of the energy carried away to the periphery back to the center of the system by converging shock waves. The collapse of the converging shock waves and initiated processes in the center of such plasma-fluid systems can be very interesting. The paper presents the results of experimental studies of pulsed cylindrical plasma-liquid system using both $\mathrm{H}_{2} \mathrm{O}$ and a mixture of $\mathrm{H}_{2} \mathrm{O} / \mathrm{D}_{2} \mathrm{O}$ and pure $\mathrm{D}_{2} \mathrm{O}$ as a liquid. The energy-storage capacitor is charged by using a high voltage DC power supply (up to $70 \mathrm{kV}$ ).
\end{abstract}

Key words:-Pulsed plasma-liquid systems, pulsed electric discharges, diverging shock waves, converging (reflected) shockwaves, discharge current.

\section{INTRODUCTION}

The results of breakdown and subsequent discharge in liquids studies have been used in a wide range of technological applications in various industries for many years. Such discharges are used for the purification of industrial wastewater containing impurities of chemical compounds and organics, the generation of various particles, including neutrons, electromagnetic radiation of various ranges, including soft X-rays [1].

During the $10 \mathrm{~s}$ and $20 \mathrm{~s}$ of the 21 st century, substantially new applications appeared with the solution of medical

Manuscript received September 08, 2021

V. Ya. Chernyak, V. V. Iukhymenko, E. V. Martysh and O. A. Nedybaliuk are with the Department of Radio Physics, Electronics and Computer Systems, Taras Shevchenko National University of Kyiv, 01601 Kyiv, Ukraine (e-mail: chernyak_v@ukr.net; yvitaliy@ukr.net).

O.A. Fedorovich, V. M. Shevel are with the Institute for Nuclear Research, National Academy of Science of Ukraine, 03680 Kyiv, Ukraine.

V. S. Popkov is with the Institute for Problems in Materials Science, National Academy of Science of Ukraine, 03113 Kyiv, Ukraine. problems in shock wave lithotripsy and surface treatment of polymers [2].

Recently, it has been proposed to use such systems to study real geological environments in a wide range of their physical characteristics [3]. Experimental studies of electric spark sources operation in a well have opened up new possibilities for exciting elastic waves in a liquid and opening up new prospects for this method using for seismic exploration purposes. In contrast to the conditions of unbounded water, where a center of expansion type source generates only longitudinal volume waves, a whole family of direct and backward waves is generated in a well. This process is connected with the presence of a cylindrical cavity and a liquid-solid interface.

The desire to enhance the effect of the shock wave from a single discharge by increasing its energy in order to intensify the extraction process, borrowed from electrohydraulic technologies, where the shock wave is the main acting factor, it leads to increased erosion of the electrodes, which contaminates the resulting extracts with metallic impurities [4].

The amplitude of the wave generated by the explosion should decrease when releasing of this energy has distribution in time. The impulse of this wave necessarily increases at the same time, so it can serve as a measure of the released energy in this case. Measurements have shown that the wave impulse recorded by the sensor in water with bubbles is at least 1.5 times greater than the wave impulse recorded by the sensor in water without them [5].

In recent years, the growing interest to the study of the conductors electrical explosion is associated with successful experiments on obtaining soft X-ray radiation by underwater wire-arrays electrical explosion in a set of institutes in Tomsk, Russia [6] and at the $Z$ generator, Sandia, USA [7]. The explosion of wires is the initial phase of plasma liners compression. The high-temperature dense plasma appears at the end of this implosion. This plasma serves as a powerful source of soft X-ray radiation (record radiation yields - about 2 MJ per pulse). The explosion of conductors itself is accompanied by the formation of a dense nonideal plasma, and the characteristics of the explosion serve as an important source of information about the transport and thermophysical properties of the nonideal plasma in the system center.

The experiments [6] were carried out in two stages, at the first stage parameters of a converging cylindrical shock waves formed by underwater wire-arrays electrical were studied. The time of the shock wave arrival on the axis of the system was determined, and the pressure behind its front was estimated from the velocity of propagation of this shock wave. At the second stage, experiments were carried out on the explosion of a tungsten microconductor in a high-pressure zone. The tungsten conductor was located along the axis of the cascade, 
and its explosion was carried out at the moment the shock wave arrived at the system axis.

Despite the fact that the parameters of the settings in [6 and 7] differed by more than an order of magnitude, there are common features. These include, for example, the delay in the time of the electrical explosion of conductors in the center of the system and, as a consequence, to the increase in the contribution of energy to the metal substance by the time of the explosion. The general properties of the explosion of wires and a discharge in a liquid are known, especially with a large value of the dielectric constant [4]. Due to the lack of a general theory of these phenomena, the accumulation of experimental material has undoubted interest. In view of the great importance of this subject, this paper is devoted to it.

\section{EXPERIMENT}

The scheme of experimental plasma-liquid system is shown in Fig. 1. The working part of the system is a cylinder with a height of $\mathrm{H}=10 \mathrm{~mm}$ and a radius of $\mathrm{R}=135 \mathrm{~mm}$. The thickness of all walls of the cylinder (5) is $50 \mathrm{~mm}$. They are made of stainless steel. In one of the bases of the system, there were 5 cylindrical channels with a diameter of $6 \mathrm{~mm}$, the centers of which were located at a distance of $125 \mathrm{~mm}$ from the axis of the system. These channels were used to inject liquid into a cylindrical cavity, gas yield from the cavity, introduce thermocouples, an acoustic sensor, and a fiber-optic line for radiation output.

The cylinder is filled with working fluid (1): $\mathrm{H}_{2} \mathrm{O}, \mathrm{D}_{2} \mathrm{O}$ or their mixture. The electrodes (2) are located at right angles to the cylinder on the axis of the system. The electrodes with a diameter of $10 \mathrm{~mm}$ are made of copper. A discharge (3) is ignited between these electrodes. Registration of acoustic signals in a plasma-liquid system was carried out using an original piezoceramic sensor (4). The signal from the sensor, placed in a liquid, passed through sealed cylindrical channel and was taken out from the plasma-liquid system. After that it entered through a voltage divider and converted into an optical signal, then was transmitted via a fiber-optic cable $8 \mathrm{~m}$ long to the input of the photoelectric converter. The electrical signal after the converter was registered with an oscilloscope (matrix MTX 1054). Optical radiation was taken out along the radius of the system through a cylindrical quartz illuminator $5 \mathrm{~mm}$ in diameter and $10 \mathrm{~mm}$ thick using fiber optic cable $2 \mathrm{~mm}$ in diameter and $200 \mathrm{~mm}$ long from a plasma-liquid system. After that it was recorded by photoelectronic multiplier (FEU-79). The fiber optic cable was inserted through a cylindrical channel at the base of the cylinder. The entrance end of the illuminator was at a distance of $5.5 \mathrm{~cm}$ from the lateral surface of the liquid cavity and was oriented perpendicular to the radius of the system.

The sensitivity of the original acoustic sensor was assessed by comparing its signals with the signal of the acoustic system of PCB Piezotronics (tourmaline pressure sensor (Model 138A51) + amplifier (Model 482C05) in a plasma-liquid system with the volume of 10 liters filled with $\mathrm{H}_{2} \mathrm{O}$. Both sensors were placed in a plane perpendicular to the cylindrical axis. The difference between the sensor signals did not exceed $5 \%$. The comparison of the signals was carried out only in the range of charging voltages up to $19.5 \mathrm{kV}$. The sensitivity of

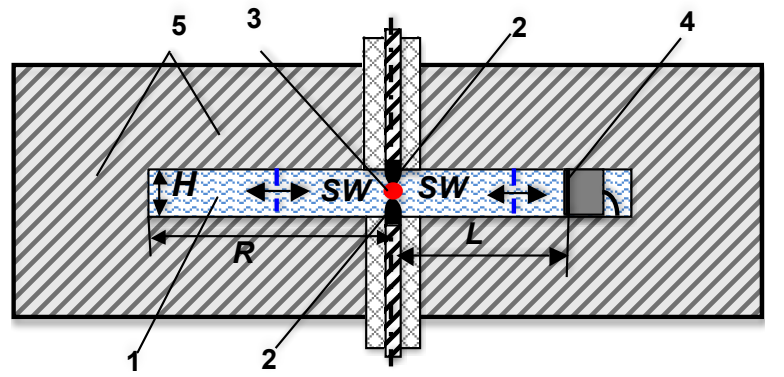

Fig. 1. Simplified scheme of experimental setup (the radius of the base is much greater than the height of the cylinder). 1- liquid, 2 - metal electrodes,

3 - discharge plasma, 4 - piezoceramic pressure sensor, 5 - cylinder walls.

the original acoustic sensor was $\sim 0.9 \mathrm{~V} / \mathrm{atm}$.

The tilt angle of the system can be changed during operation. The cylindrical system can be moved to a horizontal position (Fig. 2a), vertical (Fig. $2 \boldsymbol{b}$ ) or located at an intermediate angle (Fig. 2c). The angular position is implemented to pump gas out of the system and create a situation when the pressure sensor can be located both at the top and bottom of the system. The entire volume of the cylindrical system is filled with liquid ( 0.5 liters).

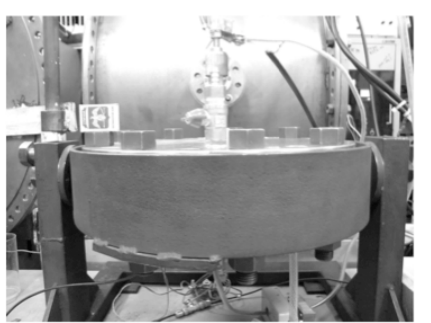

(a)

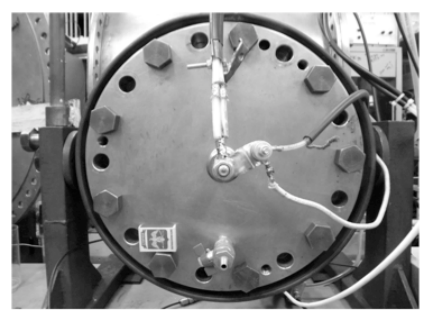

(b)

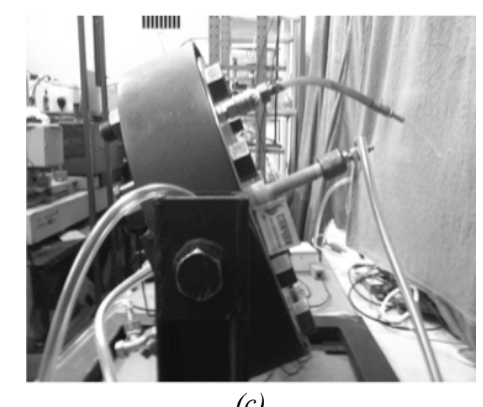

(c)

Fig. 2. Photographes of a cylindrical plasma-liquid system from the outside: (a) horizontal position, (b) vertical position, (c) angular position with an intermediate angle.

The electrical diagram of the installation is shown in Fig. 3. The installation has a capacitor bank (1), which can be charged through a ballast (3) up to $70 \mathrm{kV}$, and its capacity varies from $7.5 \mathrm{nF}$ to $67.5 \mathrm{nF}$. The capacitor bank is assembled using ceramic capacitors $\mathrm{K} 15-10(50 \mathrm{kV}, 15 \mathrm{nF})$ immersed in transformer oil. The Rogowski coil was used for current measurements. A gas-filled discharger (4) with third electrode as igniter (Fig. 4), filled with air or sulfur hexafluoride (gas $-\mathrm{SF}_{6}$ ), was used as a switching device for 
connecting a capacitor bank to a cylindrical plasma-liquid system (5).

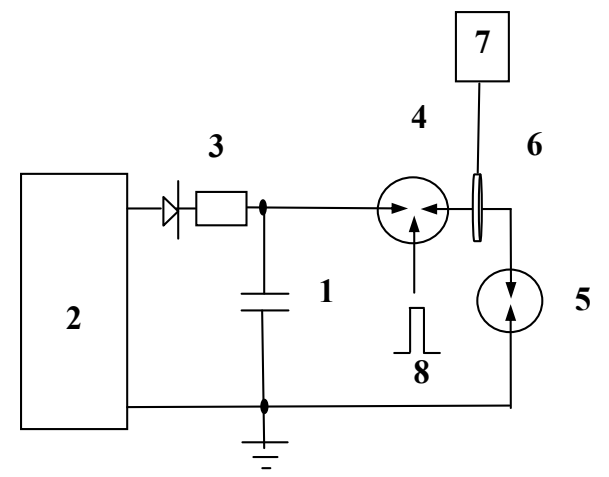

Fig. 3. Electrical circuit for generating pulsed high-voltage: 1 - capacitor bank, 2 - high voltage source, 3 - ballast resistor, 4 - switch arrestor, 5 - plasmaliquid system spark gap, 6 - Rogowski coil, 7 - oscilloscope, 8 - ignition pulse.

It is well known that gas-filled discharger (GFD) operate as a voltage-dependent switch. The principle of operation of an air-gas spark gap is based on the appearance of an avalanchelike increasing current in the interelectrode space due to ionization of air or gas when the threshold voltage on the electrodes is reached. When a voltage appears on the device that exceeds its voltage rating equal to DC breakdown voltage or when a voltage pulse is applied to the igniter electrode. the gas in the GFD begins to ionize and conduct until it reaches its impulse breakdown voltage. At this point, the device is fully on and the low arc voltage is maintained regardless of the discharge current. When the transient has passed, the GFD will return to a non-conductive state. GFD technology is capable of with standing very high impulse currents, has very high off-state insulation resistance and very low capacitance, which makes them ideal as stand-alone protection devices or as the primary stage of multi-stage circuit protection design (Fig. 4).

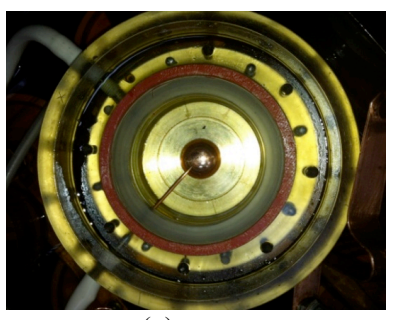

(a)

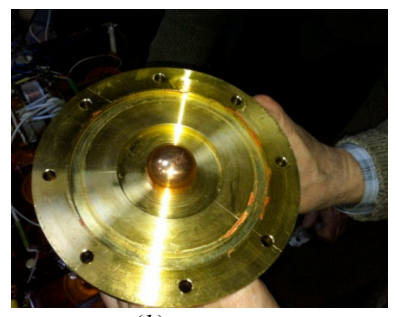

(b)
Fig. 4. Photo of the GFD electrodes.

The dependences of the discharge current and the acoustic signal (the first, second, and third diverging acoustic waves) on the energy accumulated in the condenser were studied. The distillate $\mathrm{H}_{2} \mathrm{O}, \mathrm{H}_{2} \mathrm{O} / \mathrm{D}_{2} \mathrm{O}$ mixture $(10 / 1)$ or pure $\mathrm{D}_{2} \mathrm{O}$ were working liquids, without injection and with flow injection pure $\mathrm{D}_{2} \mathrm{O}$ into the interelectrode gap and when the entire plasmaliquid system is filled with pure $\mathrm{D}_{2} \mathrm{O}$. The influence of the spatial arrangement of the cylinder with the liquid, the voltage drop across the discharge, and the time of plasma radiation were also investigated.

A gas discharge in a liquid at high voltages in a capacitor bank is inevitably accompanied by the generation of gas bubbles, which can accumulate in the system during a series of discharge pulses. As is known [8], the presence of gas bubbles significantly affects the acoustic properties of a liquid and can lead to uncontrolled changes in the measured oscillograms.

Fig. 5 shows for comparison typical oscillograms of the discharge current (lower curve) and acoustic signal (upper curve) for a series of 10 -15 pulses for the case of an open to the atmosphere of the exit of the liquid channel $-\boldsymbol{a}$ ) and sealed -b). The capacitor capacitance $\mathrm{C}=67.5 \mathrm{nF}$, charge voltage $=$ $56 \mathrm{kV}$, current sensitivity $=1.25 \mathrm{kA} / \mathrm{V}$ ( signal sensitivity on the oscilloscope was $5 \mathrm{~V} / \mathrm{grad}$ ) and pressure sensitivity 44 atm/grad (signal sensitivity on the oscilloscope $500 \mathrm{mV} / \mathrm{grad}$ ). The cylindrical system was filled with distillate and oriented horizontally. If the cylinder is closed, then a decrease in the amplitude of the acoustic signal is observed.

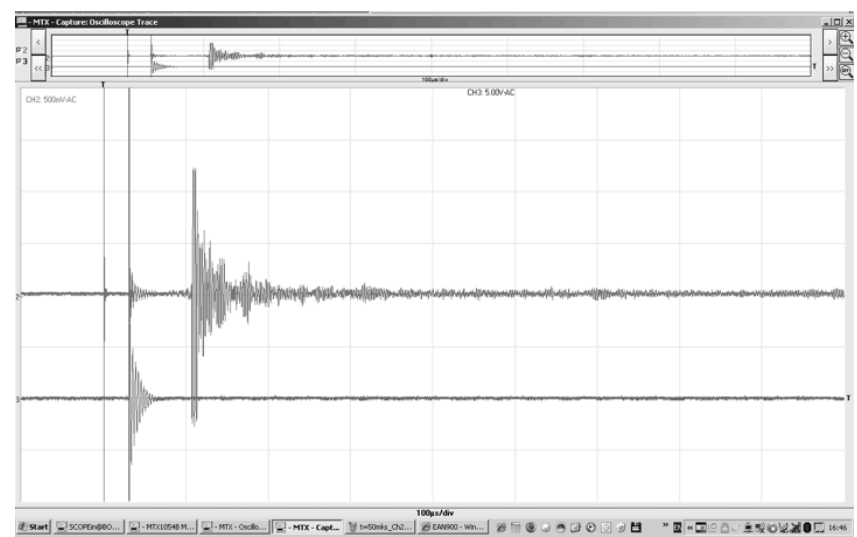

(a)

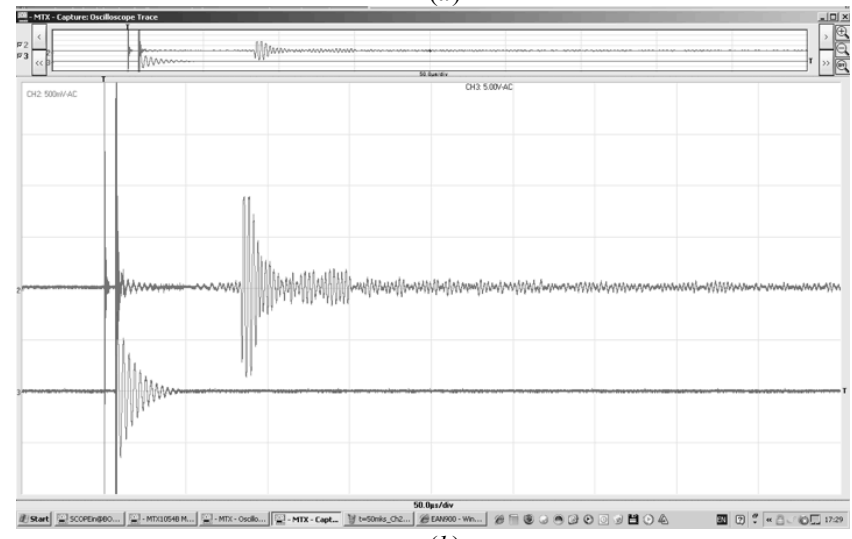

(b)

Fig. 5. Oscillograms of the discharge current (lower curve) and acoustic signal (upper curve) for a system filled with distillate. In that case $\mathrm{d}=2.5 \mathrm{~mm}$, $\mathrm{C}=67.5 \mathrm{nF}, \mathrm{U}=56 \mathrm{kV}$, the time scanning is $-100 \mu \mathrm{s} / \operatorname{grad}(\boldsymbol{a})$ and $50 \mu \mathrm{s} /$ $\operatorname{grad}(\boldsymbol{b})$.

It is obviously that distribution of gas bubbles all over the volume of the liquid will also depend on the spatial orientation of its volume. Typical oscillograms of the discharge current (upper curve) and acoustic signal (lower curve) for a series of 10-15 pulses for a plasma-liquid system filled with distillate $\left(\mathrm{H}_{2} \mathrm{O}\right)$ performed this comparison. It is shown in the Fig. 6. 
The liquid channel outlet closed to the atmosphere, but with different spatial orientation in that case: horizontal - (a) and vertical - (b). The parameter values were $\mathrm{d}=1.5 \mathrm{~mm}, \mathrm{C}=67.5$ $\mathrm{nF}, \mathrm{U}=40 \mathrm{kV}$ and the time scanning $100 \mu \mathrm{s} / \mathrm{grad}$. Discharge current sensitivity $12.6 \mathrm{kA} / \mathrm{V}$ (signal sensitivity on an oscilloscope $500 \mathrm{mV}$ /grad), acoustic measurement systems $20.24 \mathrm{~atm} / \operatorname{grad}(\boldsymbol{a})$ and $32.12 \mathrm{~atm} / \operatorname{grad}(\boldsymbol{b})$ (signal sensitivity on the oscilloscope $500 \mathrm{mV} / \mathrm{grad}$ ).

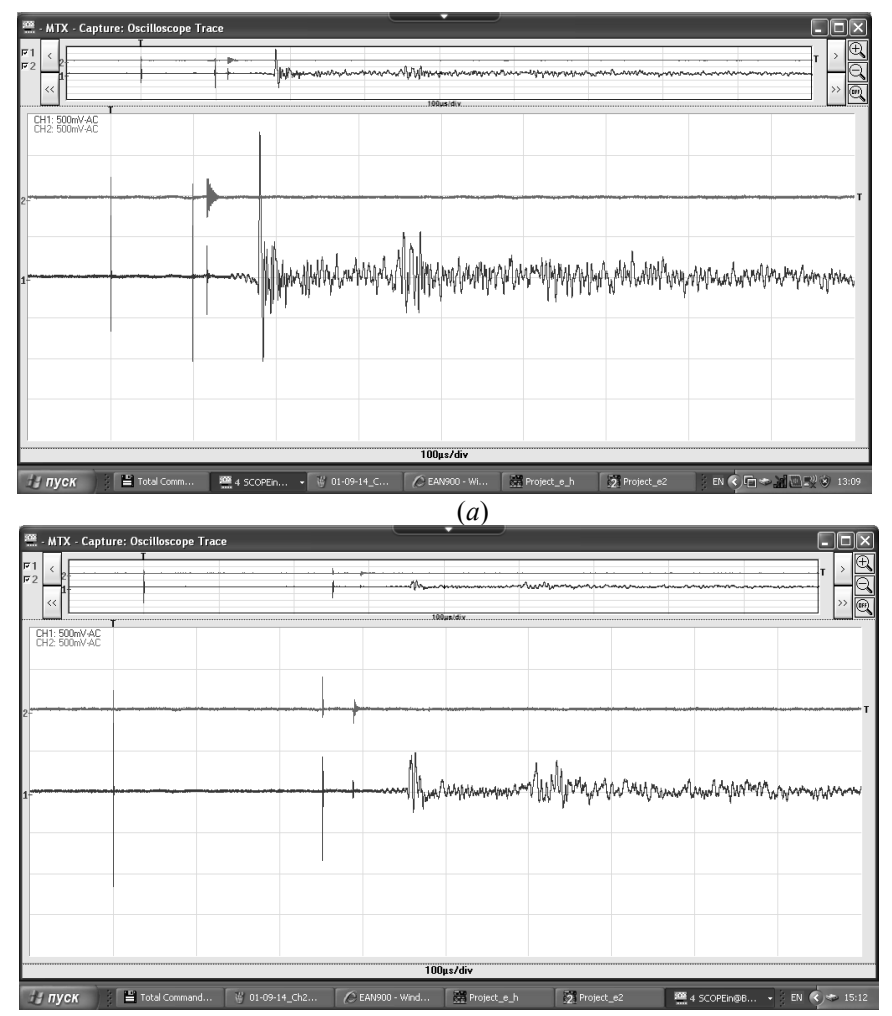

(b)

Fig. 6. Oscillograms of the discharge current (upper curve) and acoustic signal (lower curve) for a system filled with $\mathrm{H}_{2} \mathrm{O}$ and a sealed outlet of the liquid channel at different spatial orientations: horizontal - $(6 \boldsymbol{a})$ and vertical -

(6b). At d $=1.5 \mathrm{~mm}, \mathrm{C}=67.5 \mathrm{nF}, \mathrm{U}=40 \mathrm{kV}$ with time scanning 100 $\mu \mathrm{s} / \mathrm{grad}$.

Investigations of the problem: when gas accumulation in the plasma-liquid system will be possible, what is its influence on the system acoustic properties, were carried out using a distillate as a liquid. The main results of these studies are shown in Fig. 6. They demonstrated that the sealing of the plasma-liquid system leads to the reduction in magnitude of acoustic vibrations. But even with a sealed plasma-liquid system, its vertical orientation is more preferable for generating the second diverging acoustic wave, but the amplitude of the first wave is significantly higher when the system is oriented horizontally. It should also be noted that spatial orientation has no significant effect on the magnitude and type of the discharge current.

The typical oscillograms of the optical signal from the photoelectric multiplier PEM-79 (upper curve), the discharge current (middle curve) at a current sensitivity of $1.25 \mathrm{kA} / \mathrm{V}$ (the signal sensitivity on the oscilloscope is $5 \mathrm{~V} / \mathrm{grad}$ ) and an acoustic signal sensitivity is $0,07 \mathrm{~atm} / \mathrm{grad}$ (lower curve) (signal sensitivity on the oscilloscope $10 \mathrm{mV} / \mathrm{grad}$ ) are shown in Fig. 7. Their combined comparison is made to the series of 10 - 15 pulses for the plasma-liquid system with an open to atmosphere liquid channel outlet, vertically oriented, filled with a mixture of $\mathrm{H}_{2} \mathrm{O} / \mathrm{D}_{2} \mathrm{O}=10 / 1-(7 \boldsymbol{a})$, or the same mixture with an additional flow $(36 \mathrm{ml} / \mathrm{h})$ of pure $\mathrm{D}_{2} \mathrm{O}-(7 \boldsymbol{b})$ and when the entire system is completely filled with pure $\mathrm{D}_{2} \mathrm{O}$ without an additional flow of $\mathrm{D}_{2} \mathrm{O}-(7 \mathrm{c})$. The parameters of the plasma-liquid system: $\mathrm{d}=2.5 \mathrm{~mm}, \mathrm{C}=67.5 \mathrm{nF}, \mathrm{U}=56$ $\mathrm{kV}$, and the time scanning on the oscilloscope is $1 \mathrm{~ms} / \mathrm{grad}$. In process of obtaining all the oscillograms shown in this figure, the same acoustic sensor was used.

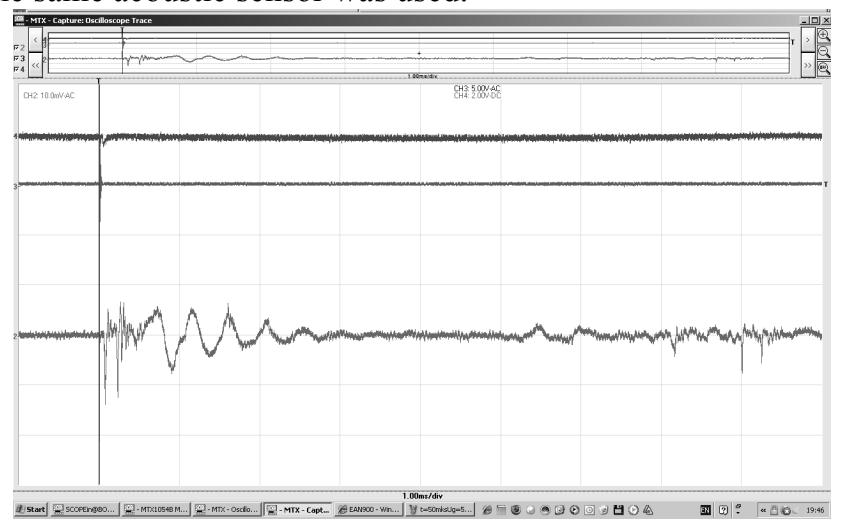

(a)

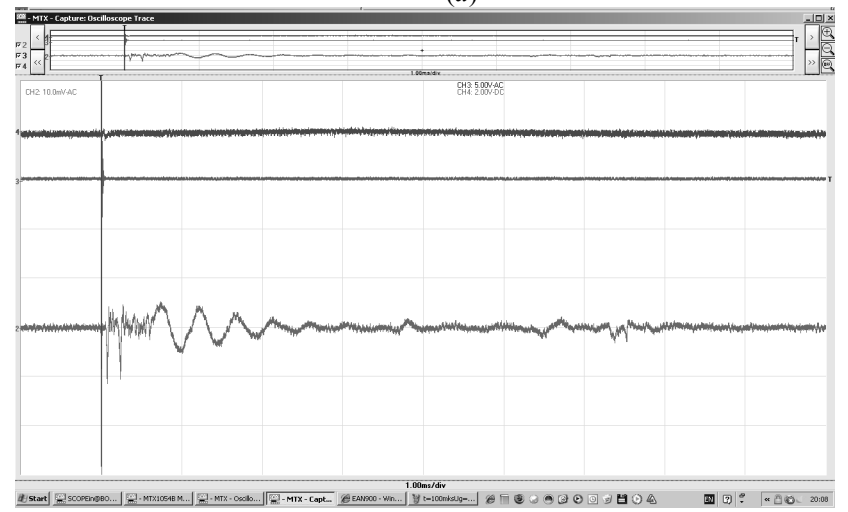

(b)

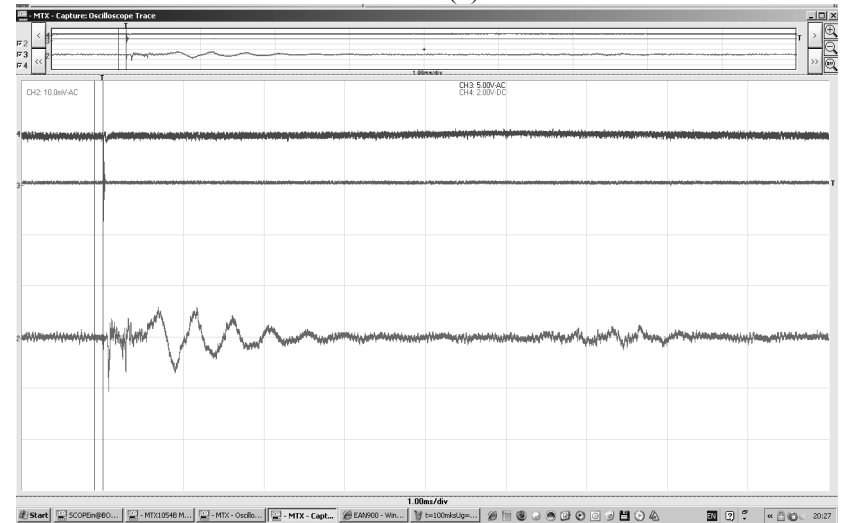

(c)

Fig. 7. Oscillograms of the optical signal from from the photoelectric multiplier PEM-79 (upper curve), discharge current (middle curve) and acoustic signal (lower curve) for a liquid channel open to the atmosphere, vertically oriented, and filled with a mixture of $\mathrm{H}_{2} \mathrm{O} / \mathrm{D}_{2} \mathrm{O}=10 / 1-(7 \boldsymbol{a})$, with a mixture of $\mathrm{H}_{2} \mathrm{O} / \mathrm{D}_{2} \mathrm{O}=10 / 1$ with an additional flow $(36 \mathrm{ml} / \mathrm{h}) \mathrm{D}_{2} \mathrm{O}-(7 \boldsymbol{b})$ and when the entire system is completely filled with pure $\mathrm{D}_{2} \mathrm{O}$ without an additional flow of $\mathrm{D}_{2} \mathrm{O}-(7 c)$. System parameters: $\mathrm{d}=2.5 \mathrm{~mm}, \mathrm{C}=67.5 \mathrm{nF}$,

$\mathrm{U}=56 \mathrm{kV}$, and the time scanning on the oscilloscope is $1 \mathrm{~ms} / \mathrm{grad}$. 
The presence of the first and second acoustic waves of the same amplitude is observed in all cases. But the presence of $100 \% \mathrm{D}_{2} \mathrm{O}(36 \mathrm{ml} / \mathrm{h})$ flow provided that amplitudes of acoustic waves have some decreasing.

\section{DISCUSSION}

The results of experiments when the plasma-liquid system was filled with $\mathrm{H}_{2} \mathrm{O}$ demonstrated that the amplitude of the first diverging wave is increasing in accompanying of the decrease in the amplitudes of the second and third diverging acoustic waves. That is occurred when the energy deposited into the discharge is increased due to an increase in the storage capacity.

This behavior of the 2 nd and 3rd acoustic waves may be due to the fact that a parasitic inductance is introduced into the system when additional capacitors are connected in the storage capacitor bank. Extra part of the energy is dissipated. When one $15 \mathrm{nF}$ capacitor is used, the amplitudes of the 1 st and $2 \mathrm{nd}$ acoustic waves are comparable. A further increase in capacitance leads to the appearance of damped oscillations in the discharge circuit and increases the duration of the discharge current pulse, which can cause perturbation of acoustic waves.

Investigation of the duration of radiation in the plasmaliquid system filled with distillate $\left(\mathrm{H}_{2} \mathrm{O}\right)$ in the specified voltage range $(\mathrm{U})$ showed that it can continue until the first collapse of the converging shock wave, which is formed by the first diverging wave reflection from the side wall of the cylinder. This can also adversely affect the amplitude of the second diverging shock wave. The generation of the first and second diverging shock waves with comparable amplitudes is observed in the plasma-liquid system during the collapse of the first converging shock wave after complete relaxation of the plasma on the axis of the system. Taking into account the energy losses of shock waves during propagation in a liquid, it can be assumed that in this case, when the first converging wave collapses, the energy density on the axis of the plasmaliquid system can be commensurate with the energy density at the moment of discharge initiation [9].

The addition of heavy water to $\mathrm{H}_{2} \mathrm{O}$ resulted in a significant amplification of acoustic signals. The transition from horizontal (Fig. 6a) to vertical orientation of the cylindrical plasma-liquid system (Fig. $6 \boldsymbol{b}$ ) also contributes to an increase of acoustic signals.

In the case of using $\mathrm{D}_{2} \mathrm{O}$ at high voltages of the capacitor bank, after the second divergent wave generation, a significant change in the acoustic signal from shock waves occurs: when the amplitudes of the first and second divergent waves are comparable, the amplitude of the third divergent wave decreases significantly. Further, a significantly different picture arises - damped acoustic oscillations with a period $\sim 3$ times larger than the time interval between the first and second diverging shock waves. This may be due to the fact that the collapse of the second converging wave leads to the formation of a gas bubble on the axis of the system, which begins to efficiently absorb acoustic energy from the converging shock waves, and then begins to generate its own acoustic waves. The presence of the first and second acoustic waves of the same amplitude is observed in all experiments in the presence of $\mathrm{D}_{2} \mathrm{O}\left(\mathrm{H}_{2} \mathrm{O} / \mathrm{D}_{2} \mathrm{O}\right.$ mixture $=10 / 1$ or pure $\left.\mathrm{D}_{2} \mathrm{O}\right)$. However, the amplitudes of the acoustic waves are somewhat less in the presence of a flow of $100 \% \quad \mathrm{D}_{2} \mathrm{O} \quad(36 \mathrm{ml} / \mathrm{h})$ into the interelectrode gap.

The speed of the acoustic waves propagation is $\sim 1500 \mathrm{~m} / \mathrm{s}$ in the plasma-liquid system filled with $\mathrm{H}_{2} \mathrm{O}$ distillate or mixture of $\mathrm{H}_{2} \mathrm{O} / \mathrm{D}_{2} \mathrm{O}=10 / 1$. That is comparable to the speed of sound in $\mathrm{H}_{2} \mathrm{O}$. The system filled with pure $\mathrm{D}_{2} \mathrm{O}$ has speed of acoustic waves propagation $\sim 1400 \mathrm{~m} / \mathrm{s}$.

\section{RADIOMETRY RESULTS}

Four sensors-dosimeters which have sensitive to X-rays and neutrons were fixed on the end walls of a cylindrical reactor when conducting studies using $\mathrm{D}_{2} \mathrm{O}$ when filling a cylindrical plasma-liquid system with a mixture of $\mathrm{H}_{2} \mathrm{O} / \mathrm{D}_{2} \mathrm{O}$ or pure $\mathrm{D}_{2} \mathrm{O}$ for 2 days and 2 months as a total period after zero annealing.

We used the thermoluminescent dosimeter TLD-500 which is based on single crystals of lithium fluoride (LiF) in a special packaging as radiation-measurement equipment. Packages of 4 dosimeters, 5 pieces of single crystals in each, were located on the outer surfaces of the bases of the cylindrical reaction chamber. There are two on each base at $15 \mathrm{~cm}$ away from the center of a base. Also, similar 4 packs of dosimeters (background) were placed on each wall of the laboratory at a distance of $\sim 3 \mathrm{~m}$ from the camera, in the control room. The power value of the equivalent dose on the bases of the reaction chamber exceeded the value indication of background dosimeters on the walls of the laboratory by 1.5-1.9 times. The value indication of the equivalent dose comes to 0.37 microsieverts per hour $(\mu \mathrm{Sv} / \mathrm{h})$.

A gas-discharge dosimeter with Geiger-Muller selfquenched counter STS-6 (sts-6-schetchik) directly near the plasma-liquid system recorded a doubling of the radiation level ( 0.20 microsievert per hour) within 10 minutes after a single pulse discharge at $U=70 \mathrm{kV}$. During the day before the experiment and 30 minutes after the experiment, the indications of this dosimeter varied within 8-10. The sensitivity of the gas-discharge dosimeter was calibrated using a universal dosimeter-radiometer "MKS-U".

\section{SUMMARY}

- Analysis of the entire set of research results indicates the promise of inertial heating systems using the pulsed plasmaliquid systems with heavy water and reflection of shock waves from massive walls with sizes of much longer acoustic wavelengths for obtaining the collapse of converging shock waves in a liquid after complete relaxation of the plasma. It is formed with a powerful pulse of electric discharge.

- Investigation of the cylindrical plasma-liquid system at $\mathrm{R}>>$ $\mathrm{h} \sim \mathrm{d}$ showed that pulsed electric discharge effectively generates acoustic oscillations, the amplitude of which depends not only on the properties of the liquid and the electrophysical parameters of the discharge, but also on the orientation of the system in space and the conditions for the egestion of gases generated by a discharge in a liquid.

- Sealing of the plasma-liquid system leads to a decrease in the amplitude of acoustic vibrations. But even with a sealed plasma-liquid system, the vertical orientation of the cylindrical 
system is more preferable to generate a second diverging acoustic wave.

- In plasma-liquid systems filled with a mixture of $\mathrm{H}_{2} \mathrm{O} / \mathrm{D}_{2} \mathrm{O}$ $=10 / 1$ or pure $\mathrm{D}_{2} \mathrm{O}$, the presence of the first and second diverging acoustic waves of the same amplitude (commensurable amplitudes) is observed.

\section{REFERENCES}

[1] B. Sun, "Discharge Plasma in Liquid and its Applications". Beijing, China: Science Press, 2013.

[2] A. Srisubat, S. Potisat, B. Lojanapiwat, V. Setthawong, M. Laopaiboon, "Extracorporeal shock wave lithotripsy (ESWL) versus percutaneous nephrolithotomy (PCNL) or retrograde intrarenal surgery (RIRS) for kidney stones". The Cochrane Database of Systematic Reviews. No 11, 24 November 2014.

[3] M.L. Vladov, "Seismoacoustic multiwave studies in water-filled wells using an electric spark source of elastic waves". Thesis for a Doctor's degree, 2003.

[4] E.E. Son, V.E. Fortov, Kh.Kh. Azmeev and others. "Electrophysics and explosion safety of high-voltage oil-filled electrical equipment" (in Russian) - Moscow, Russia: RAS, 2019.

[5] G.G. Oganyan, "Increase in the compression wave amplitude in a liquid with dissolved-gas bubbles". Fluid Dyn 40, pp.95-102, 2005.

[6] A.G. Russkikh, V.I. Oreshkin, A.U. Labeckij, S.A. Chaikovsky and A.V. Shishlov, "Investigation of the electrical explosion of conductors in the high-pressure zone of a converging shock wave," Zh. Tekh. Fiz., vol. 77, no. 5, pp. 35-40, 2007.

[7] D. B. Sinars, M. A. Sweeney, C. S. Alexander and other, "Review of pulsed power-driven high energy density physics research on $\mathrm{Z}$ at Sandia". Phys. Plasmas 27, 070501, 2020.

[8] M. J. Kushner, N. Yu. Babaeva, "Plasma Production in Liquids: Bubble and Electronic Mechanism". Proceeding of the Bulletin of the APS GES10, Paris, France, October 4-8, 2010.

[9] R.R. Buntzen, "The use of exploding wires in the study of low-power underwater explosions", pp.225-238, in Electric Explosion of Conductors (in Russian). (Mir, Moscow, 1965).

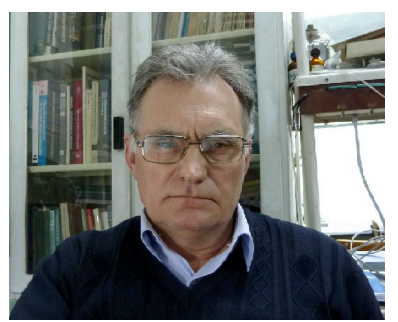

Valeriy Ya. Chernyak was born in Kyiv, Ukraine, in 1948. He received the M.S., Ph.D., D.Sc., and Professor degrees from Kyiv National Taras Shevchenko University, Kyiv, Ukraine, in 1969, 1973, 2005, and 2008, respectively, all in physics and electronics. He was conscripted in 1972 and served in the army until 1974. He was an Assistant Professor, an Associate Professor, and a Lecturer with the Faculty of Radio Physics, Electronics and Computer Systems, Taras Shevchenko National University of Kyiv, where he is currently a Professor. He is also the Head of the Department of Physical Electronics, Plasma Chemical Research Team, Kyiv National Taras Shevchenko University. He has authored over 300 publications and presented many invited lectures in international conferences and workshops. His current research interests include nonequilibrium plasma chemistry and its applications, particularly plasma-assisted reforming of liquid hydrocarbons.

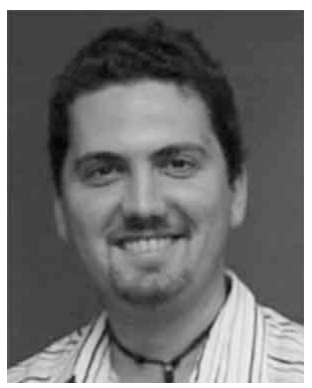

Vitaliy V. Iukhymenko was born in Kyiv, Ukraine, in 1980. He received the M.S. degree in radio physics and electronics and the Ph.D. degree in plasma physics from the Taras Shevchenko National University of Kyiv, Kyiv, Ukraine, in 2002 and 2013, respectively.

From 2002 to 2004 and from 2008 to 2013, he was an Engineer with the Taras Shevchenko National University of Kyiv. He was a Junior Researcher from 2013 to 2015. From 2016 to 2018 he was a Researcher. Since 2018 he has been the Head of the Research and Development Sector of the Theory and Modeling of Plasma Processes with the Taras Shevchenko National University of Kyiv. His current research interests include physics of low-temperature plasma, plasma chemistry, plasma-assisted decomposition of organic pollutants in water solutions, reforming of bio-fuel in plasma-liquid systems, synthesis of organic compounds and plasma spectroscopy.

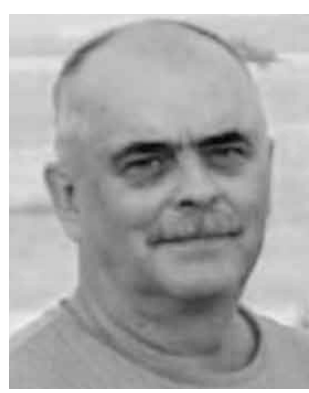

Evgen V. Martysh was born in Viliany, Latvia, in 1952. He received the M.S., Ph.D., and D.Sc. degrees in plasma physics from the Taras Shevchenko National University of Kyiv, Kyiv, Ukraine, in 1976, 1983, and 2009, respectively

He is currently the Head of the Department of Medical Radio Physics, Faculty of Radio Physics, Elctronics, and Computer Systems, Taras Shevchenko National University of Kyiv. He hasauthored over 100 publications. He holds one patent. His current research interests include the physics of heterophase electric discharge plasmas and their applications.

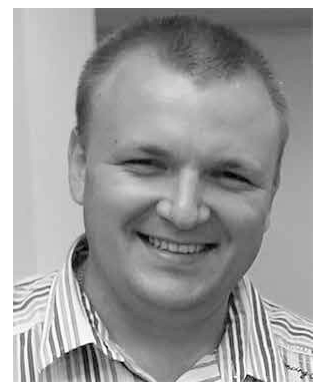

Oleg A. Nedybaliuk was born in Murafa, Ukraine, in 1985. He received the M.S. degree in radio physics and electronics and the Ph.D. degree in plasma physics from the Taras Shevchenko National University of Kyiv, Kyiv, Ukraine, in 2008 and 2012, respectively.

From 2011 to 2012, he was a First-Class Engineer with the Taras Shevchenko National University of Kyiv. He was a Junior Researcher from 2012 to 2014. From 2014 to 2018 he was the Head of the Research and Development Sector of the Theory and Modeling of Plasma Processes, Taras Shevchenko National University of Kyiv. Since 2018 he has been Assistance lecturer with the Taras Shevchenko National University of Kyiv. His current research interests include plasma-liquid systems, rotating gliding discharge, plasma and plasma-catalytic reforming of liquid hydrocarbons into synthesis gas, optical emission spectroscopy of plasma, plasma-assisted combustion of hydrocarbons, and the influence of plasma on the surface tension of the liquids.

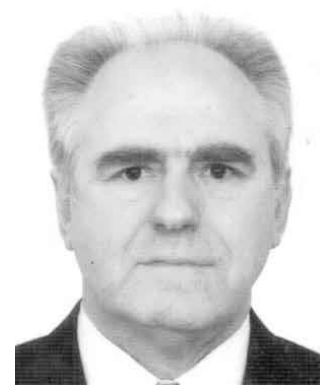

Volodymyr S. Popkov was born in Chernatske, Ukraine, in 1940. He received the M.S. degree in electrical engineering from the Kyiv Polytechnic Institute, Kyiv, Ukraine, in 1968.

He was the Head Project Constructor with the Special Constructor Bureau of Linear Electric Engines and as the Head of the Department of Theory and Calculations. Since 2008, he has been a Lead Engineer with the Institute for Problems in Materials Science, National Academy of Science of Ukraine, Kyiv. He holds over 265 patents and publications. His current research interests include the electro-mechanical devices and alternative energy. 


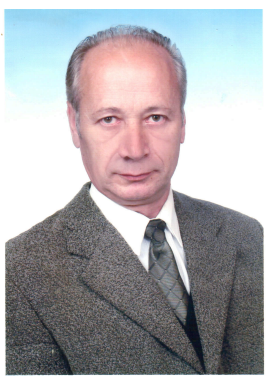

Oleh A. Fedorovich was born in Vovkovyntsi, Ukraine in 1949.

He received M.S. in physics and electrical engineering from Kamyanets-Podilsky Ivan Ohienko National University in 1971 and Ph.D. from degree in plasma physics and chemistry from the Joint Institute for High Temperatures (JIHT), RAS in 1988. He is currently the Head of the Department of Plasma Physics and Plasma Technologies in the Institute for nuclear researches of the NAS of Ukraine. His major research interests include physics research of dense plasma, high-frequency discharges for plasma-chemical technologies, and the interaction of low-energy hydrogen ions with various metals.

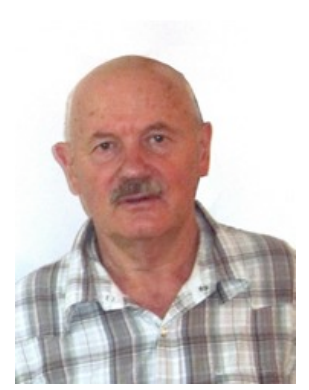

Valerii Myc. Shevel was born in Kryvoy Rog, Ukraine, in 1944.

Deputy Chief Reactor Engineer of the Research Nuclear Reactor Department, , higher education, graduated from Dnepropetrovsk State University in 1968. specialty - physicist, nuclear physics.

Shevel VM has been operating at a nuclear reactor since March 1973. holding the positions of senior engineer of the reactor radiation safety service, chief of the reactor radiation safety service, chief of the reactor radiation control service, deputy chief engineer of the reactor radiation safety, deputy chief engineer of radiation technology, deputy chief engineer of radiation technology and radiation control. 